\title{
Antiproliferative effect of ME3738, a derivative of soyasapogenol, on hepatocellular carcinoma cell lines in vitro and in vivo
}

\author{
SACHIKO OGASAWARA ${ }^{1}$, JUN AKIBA ${ }^{2}$, MASAMICHI NAKAYAMA $^{1}$, \\ HIRONORI KUSANO $^{1}$ and HIROHISA YANO ${ }^{1}$ \\ ${ }^{1}$ Department of Pathology, Kurume University School of Medicine; \\ ${ }^{2}$ Department of Diagnostic Pathology, Kurume University Hospital and Kurume \\ University School of Medicine, Kurume, Fukuoka 830-0011, Japan
}

Received June 14, 2016; Accepted October 17, 2016

DOI: $10.3892 /$ br. 2016.792

\begin{abstract}
Soyasapogenol, an aglycon of soyasaponin, ameliorates liver injury induced by concanavalin $\mathrm{A}$ in mice. A derivative of soyasapogenol, 22 $\beta$-methoxyolean-12-ene-3 $\beta$, $24(4 \beta)$-diol (ME3738), was reported to induce the gene expression of interferon (IFN)- $\beta$ in hepatitis $C$ virus replicon cells. The effect of ME3738 on hepatocellular carcinoma (HCC) cell lines was investigated in the present study. A total of $11 \mathrm{HCC}$ cell lines were cultured in medium containing 0-10 $\mu \mathrm{M}$ ME3738, and after 24,48 , or 72 h of culture, morphological observation and MTT cell growth assays were performed. Furthermore, the effects of ME3738 with or without PEG-IFN- $\alpha-2 b$ on cell lines were investigated. Induction of apoptosis was examined on cells treated with $1 \mu \mathrm{M}$ of ME3738 using an Annexin V assay. The effect of ME3738 (0.63 and $2.5 \mu \mathrm{M})$ on cell cycle progression was analyzed on two cell lines. The mice with subcutaneous tumors were divided into four groups: i) Control; ii) ME3738 alone; iii) PEG-IFN- $\alpha-2 b$ alone and iv) ME3738+PEG-IFN- $\alpha-2 b$ (combination). ME3738 was mixed with food $(1.5 \mathrm{mg} / \mathrm{g})$ and was taken orally for 15 days. PEG-IFN- $\alpha$-2b (1,920 IU/mouse) was subcutaneously injected twice a week for two consecutive weeks. On day 15, the mice were sacrificed and the tumors were resected. A dose-dependent anti-proliferative effect was observed to various degrees in all the HCC cell lines in vitro. This inhibitory effect reached its maximal level $24 \mathrm{~h}$ after the treatment and the $50 \%$ inhibitory dose was between 0.8 and $2.4 \mu \mathrm{M}$. The combination treatment did not show a synergistic effect. Induction of apoptosis was not observed. Cell cycle arrest at S-phase was observed in two of the examined cell lines. On day 15, the tumor volume of mice receiving ME3738, PEG-IFN- $\alpha-2 b$, and ME3738+PEG-IFN- $\alpha-2 b$ was 69,30 , and $33 \%$, respectively,
\end{abstract}

Correspondence to: Dr Sachiko Ogasawara, Department of Pathology, Kurume University School of Medicine, 67 Asahi-machi, Kurume, Fukuoka 830-0011, Japan

E-mail: sachiko@med.kurume-u.ac.jp

Key words: HCC, HCV, ME3738, IFN, soyasapogenol of the control tumor volume. ME3738 induced antiproliferative effects on the HCC cells in vitro and in vivo. The data suggested potential clinical application of ME3738.

\section{Introduction}

Soyasaponin is classified among the sugar conjugates of triterpenes, and can take various chemical and sugar-chain structures, such as soyasapogenol. Numerous saponins have demonstrated antimutagenic, anticarcinogenic and antimetastatic effects against multiple cell lines (1). Triterpenoid saponins are natural sugar conjugates of triterpenes that possess various biological effects. Soyasaponin exerts antiviral effects on herpes simplex virus, human cytomegalovirus, influenza virus, and human immunodeficiency virus through its suppression of gene and viral protein synthesis $(2,3)$. Soyasaponin was reported to suppress cancer cell growth in the colon cancer cell lines (4-6), and reduced colon cancer rates were identified in individuals who consume large amounts of soy legumes (7), suggesting that soyasaponins may have a protective effect against colon cancer. In addition, soyasaponin showed hypotensive action in spontaneous hypertension (8).

Soyasapogenol, an aglycon of soyasaponin, extracted from Glycine max Merr, 22 $\beta$-methoxyolean-12-ene-3 $\beta$, 24(4 $\beta$ )-diol (ME3738) is a derivative of soyasapogenol B. ME3738 has been reported to ameliorate liver damage in several experimental models of acute and chronic liver injury induced by concanavalin A (Con A), ethanol, lithocholate, and bile duct ligation (9-13).

ME3738 induces interleukin-6 (IL-6) expression, and serum amyloid $\mathrm{A}$ and $\alpha 1$ acid glycoprotein as downstream targets of the IL- 6 signal protecting against Con A-induced liver injury.

Hepatocellular carcinoma (HCC) is one of the most common cancer types worldwide and a leading cause of cancer mortality, especially in countries with a high prevalence of chronic infections with hepatitis $B$ virus and hepatitis $C$ virus (HCV). ME3738 suppresses HCV replication by inhibiting mRNA in HCV replicon cells, along with NS3 and core proteins (14). Saibara et al treated chronic hepatitis $C$ patients for 48 weeks with a combination of PEG interferon (IFN)- $\alpha-2 b$ and ME3738 (15). Authors of that study reported that the 
subjects became HCV RNA-negative during the administration, and that combination treatment was very safe with no side effects other than those seen with PEG IFN- $\alpha-2 b$ alone. ME3738 is effective in treating chronic hepatitis C, however, to the best of our knowledge, there are no reports available on the effect of ME3738 on HCC. In the present study, we investigated the antiproliferative effects of ME3738 on HCC cell lines.

\section{Materials and methods}

Cell lines and cell culture. The present study used 11 HCC cell lines (KIM-1, KYN-1, KYN-2, KYN-3, HAK-1A, HAK-1B, HAK-2, HAK-3, HAK-4, HAK-5 and HAK-6). The HCC cell lines were originally established in our laboratory, and each cell line retained the morphological and functional features of the original tumor as described elsewhere (16-22). The cells were grown in Dulbecco's modified Eagle's medium (Nissui Pharmaceutical, Tokyo, Japan) and supplemented with $2.5 \%$ heat-inactivated $\left(56^{\circ} \mathrm{C}, 30 \mathrm{~min}\right)$ fetal bovine serum (Bioserum, Victoria, Australia), $100 \mathrm{U} / \mathrm{ml}$ penicillin, $100 \mu \mathrm{g} / \mathrm{ml}$ streptomycin (Gibco BRL, Gaithersburg, MD, USA) and $12 \mathrm{mmol} / \mathrm{l}$ sodium bicarbonate, in a humidified atmosphere of $5 \% \mathrm{CO}_{2}$ in air at $37^{\circ} \mathrm{C}$.

Effects of ME3738 on the proliferation of HCC cell lines in vitro. The cells $\left(1.5-6.5 \times 10^{3}\right.$ cells/well) were seeded $96-$ well plates (Thermo Fisher Scientific, Roskilde, Denmark), cultured for $24 \mathrm{~h}$ and the medium was replaced with ME3738 (Meiji Seika Pharm Co., Ltd., Tokyo, Japan; 0, 0.08, 0.16, 0.32, 0.63, $1.25,2.5,5$ and $10 \mu \mathrm{M})$. After culturing for 24,48 or $72 \mathrm{~h}$, the number of viable cells was examined using MTT cell growth assay kits (Chemicon International, Inc., Temecula, CA, USA). The $50 \%$ inhibitory concentration $\left(\mathrm{IC}_{50}\right)$ of each cell line was estimated at $24 \mathrm{~h}$ of culture with ME3738.

Quantitative analysis of ME3738-induced apoptosis in vitro. Cells cultured with or without ME3738 $(1 \mu \mathrm{M})$ for $72 \mathrm{~h}$ were stained with the Annexin V-enhanced green fluorescent protein (EGFP) Apoptosis Detection kits (Medical and Biological Laboratories Co., Ltd., Nagoya, Japan) according to the manufacturer's protocol. After staining, the cells were analyzed using a FACScan (BD Biosciences, San Jose, CA, USA), and the Annexin V-EGFP-positive apoptotic cell rate was determined.

Effects of ME3738 on cell cycle. HAK-1B and HAK-4 were cultured with ME3738 $(0.63$ or $2.5 \mu \mathrm{M})$ for 12,24 or $48 \mathrm{~h}$, labeled with $10 \mu \mathrm{M}$ BrdU for $30 \mathrm{~min}$, fixed in $70 \%$ cold ethanol at $4^{\circ} \mathrm{C}$ overnight, stained with anti-BrdU and propidium iodide, and then analyzed using a FACScan. Staining was performed using the modified technique described elsewhere (23).

Effects of ME3738 with or without PEG-IFN- $\alpha-2 b$ on the proliferation of $H C C$ cell lines in vitro. The cells (1.5-6.5x10 ${ }^{3}$ cells/well) were seeded in 96-well plates (Thermo Fisher Scientific), cultured for $24 \mathrm{~h}$ and the medium was replaced with ME3738 $(0,0.1$ or $0.5 \mu \mathrm{M})$ with or without PEG-IFN- $\alpha-2 b$ (PEGIntron ${ }^{\circledR}$; MSD K.K., Tokyo, Japan; 0 or $1,000 \mathrm{IU} / \mathrm{ml})$. After culturing for $72 \mathrm{~h}$, the number of viable cells was examined using MTT cell growth assay kits (Chemicon International, Inc.).

Effects of ME3738 with or without PEG-IFN- $\alpha-2 b$ on the proliferation of $\mathrm{HCC}$ cell lines in $\mathrm{BALB} / \mathrm{c}$ mice. HAK-1B cells $\left(1 \times 10^{7}\right.$ cells/mouse) were transplanted subcutaneously into the backs of 4-week-old female BALB/c mice. After tumor formation was confirmed, the mice were divided into four groups ( $n=7$ in each group), i.e., control group, ME3738 alone group, PEG-IFN- $\alpha-2 b$ alone group and ME3738+PEG-IFN- $\alpha-2 b$ (combination) group. ME3738 was mixed with food $(1.5 \mathrm{mg} / \mathrm{g})$ and was taken orally for 15 days. PEG-IFN- $\alpha-2 b$ $(1,920 \mathrm{IU} / \mathrm{mouse})$ was subcutaneously injected twice a week for two consecutive weeks. The clinical dose of PEG-IFN- $\alpha-2 b$ in chronic hepatitis $\mathrm{C}$ treatment was $9.6 \times 10^{4} \mathrm{IU} / \mathrm{kg}$ and was 3 -fold that of the lowest dose $\left(3.2 \times 10^{4} \mathrm{IU} / \mathrm{kg}\right)$ in the experiment. The tumor size was measured in two directions using calipers (until day 15$)$, and the tumor volume $\left(\mathrm{mm}^{3}\right)$ was estimated using the equation 'length $\mathrm{x}$ (width) ${ }^{2} \mathrm{x} 0.5$ '. On day 15 , the mice were sacrificed by cervical dislocation and the resected tumor was fixed in formalin and prepared into paraffin sections.

In addition, immunostaining was performed with anti-mouse endothelial cell antibody (anti-mouse CD34 monoclonal antibody, clone MEC14.7, final dilution, 1/100, cat. no. MCA1825; AbD Serotec, Raleigh, NC, USA) and anti-human Ki-67 monoclonal antibody (clone MIB-1, final dilution, 1/50, cat. no. M724029; Dako, Carpinteria, CA, USA).

The number of blood vessels and MIB-1 index in a unit area $\left(\mathrm{mm}^{2}\right)$ of every section was calculated and its mean was obtained.

The present study was approved by the Ethics Committee of Kurume University (approval no. 10248). Animal experiments for the current study were approved by the Ethics Review Committee for Animal Experimentation of Kurume University School of Medicine.

Statistical analysis. Data are expressed as the mean \pm standard deviation. Comparisons between groups were performed using Student's t-test and two-factor factorial ANOVA. $\mathrm{P}<0.05$ was considered to indicate a statistically significant difference.

\section{Results}

Effects of ME3738 on the proliferation of HCC cell lines in vitro. In all the cell lines, a dose-dependent antiproliferative effect was observed at various degrees in 24, 48 and $72 \mathrm{~h}$ cultures with ME3738. The cell number was suppressed in 10 cell lines to $<50 \%$ of the control at $24 \mathrm{~h}$ (Fig. 1) and the suppression was statistically significant in all the cell lines with a dose range of $0.08-10 \mu \mathrm{M}(\mathrm{P}<0.001)$. The $\mathrm{IC}_{50}$ of ME3738 cultured for $24 \mathrm{~h}$ was $0.8-2.4 \mu \mathrm{M}$, with the exception of KYN-2 (Table I).

Quantitative analysis of ME3738-induced apoptosis in vitro. Quantitative analysis of apoptosis revealed ME3738 did not induce a significant increase in the amount of apoptosis (Table II).

Effects of ME3738 on cell cycle. In HAK-1B and HAK-4, the ratio of the cells in the $\mathrm{S}$-phase increased, and ratio of the 
Table I. $\mathrm{IC}_{50}$ of ME3738 in the cell lines.

\begin{tabular}{lc}
\hline Cell line & $\mathrm{IC}_{50}(\mu \mathrm{M})$ \\
\hline KIM-1 & 1.8 \\
KYN-1 & 2.0 \\
KYN-2 & $\mathrm{ND}$ \\
KYN-3 & 2.0 \\
HAK-1A & 2.0 \\
HAK-1B & 0.8 \\
HAK-2 & 1.9 \\
HAK-3 & 1.2 \\
HAK-4 & 1.4 \\
HAK-5 & 1.1 \\
HAK-6 & 2.4
\end{tabular}

ND, not determined.

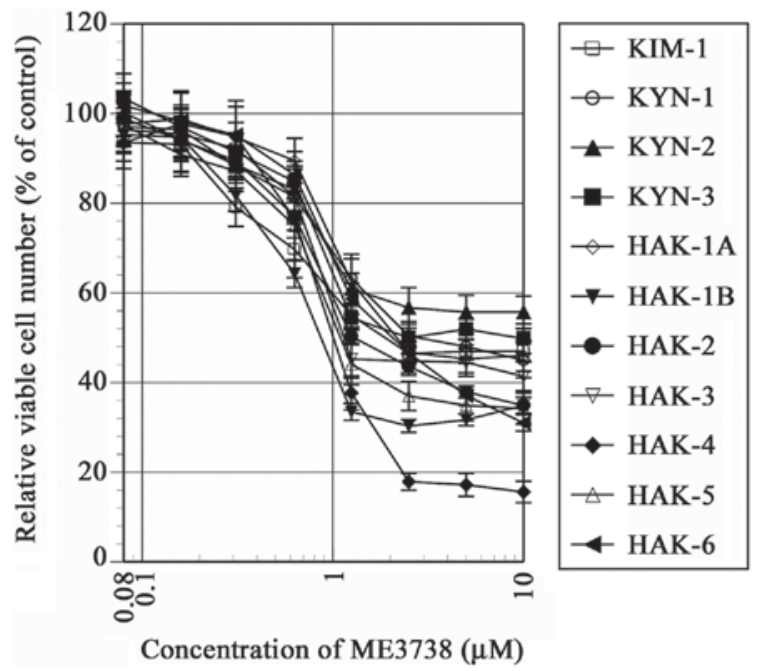

Figure 1. Antiproliferative effect of ME3738. In all the cell lines, a dose-dependent antiproliferative effect was observed at various degrees in $24 \mathrm{~h}$ cultures with ME3738. The suppression was statistically significant in all the cell lines at a dose range of $0.08-10 \mu \mathrm{M}(\mathrm{P}<0.001)$. ME3738, $22 \beta$-methoxyolean-12-ene-3 $\beta, 24(4 \beta)$-diol.

cells in the G2/M phase slightly decreased or did not change, compared with those in the control cells at any time-point 12-48 $\mathrm{h}$ after the addition of ME3738 (Fig. 2).

Effects of ME3738 with or without PEG-IFN- $\alpha-2 b$ on the proliferation of HCC cell lines in vitro. A total of $72 \mathrm{~h}$ after the addition of PEG-IFN- $\alpha-2 b$ alone, the relative viable cell number was suppressed in all the cell lines. The combination treatment of ME3738 and PEG-IFN- $\alpha-2 b$ did not exert synergistic antiproliferative effects in any cell lines (Fig. 3).

Effects of ME3738 with or without PEG-IFN- $\alpha-2 b$ on the proliferation of HCC cell lines in nude mice. On day 15, the tumor volume of mice receiving ME3738 $(\mathrm{P}<0.05)$, PEG-IFN- $\alpha-2 b(P<0.001)$, and ME3738+PEG-IFN- $\alpha-2 b$ $(\mathrm{P}<0.001)$ was $69.3,30.9$, and $33.5 \%$, respectively, of the
Table II. Quantitative analysis of apoptosis induced by ME3738 in 11 liver cancer cell lines.

Annexin V-EGFP-positive apoptotic cells (\%)

\begin{tabular}{lrr}
\cline { 2 - 3 } Cell line & Control & ME3738 \\
\hline KIM-1 & $6.4 \pm 1.3$ & $9.1 \pm 2.1$ \\
KYN-1 & $9.6 \pm 1.1$ & $10.7 \pm 0.8$ \\
KYN-2 & $13.6 \pm 3.2$ & $16.8 \pm 1.5$ \\
KYN-3 & $6.9 \pm 1.3$ & $6.9 \pm 1.3$ \\
HAK-1A & $7.9 \pm 1.6$ & $7.3 \pm 3.5$ \\
HAK-1B & $12.9 \pm 1.8$ & $12.8 \pm 2.1$ \\
HAK-2 & $8.6 \pm 2.4$ & $7.9 \pm 2.0$ \\
HAK-3 & $9.2 \pm 1.9$ & $9.9 \pm 0.8$ \\
HAK-4 & $6.3 \pm 2.1$ & $5.3 \pm 1.8$ \\
HAK-5 & $7.9 \pm 1.2$ & $7.1 \pm 0.8$ \\
HAK-6 & $5.4 \pm 3.4$ & $5.6 \pm 2.9$
\end{tabular}

Cells were cultured with medium alone (control) or medium with $1 \mu \mathrm{M}$ of ME3738. Apoptosis was measured by Annexin V-EGFP staining. EGFP, enhanced green fluorescent protein.

control tumor volume (Fig. 4). The MIB-1 index showed $>70 \%$ positive cells in all the groups, and there were no significant differences in the mean number of blood vessels per unit area among the groups (data not shown).

\section{Discussion}

We have previously reported that PEG-IFN- $\alpha-2 b$ and IFN- $\beta$, which are widely used in the treatment of $\mathrm{HCV}$, suppress cell proliferation by inducing apoptosis and/or cell cycle arrest in many HCC cell lines $(23,24)$. However, some cell lines showed low sensitivity for PEG-IFN- $\alpha-2 b$ and IFN- $\beta$ on proliferation. By contrast, ME3738 was able to suppress cell proliferation at various concentrations in all the cell lines we studied, including those with low sensitivity to IFN. Even KYN-2, which had the lowest degree of cell suppression, showed a $40 \%$ inhibition of cell proliferation at doses of $\geq 1.25 \mu \mathrm{M}$.

The findings of the present study suggest that the suppression of HCC cell proliferation by ME3738 was due, not to apoptosis, but rather to the inhibition of cell cycle progression. ME3738 upregulates the production of IFN- $\beta$ in non-neoplastic liver cells (25). We examined the effect of ME3738 on IFN- $\beta$ expression in HAK-1B cells by microarray, but no change in IFN- $\beta$ expression was observed (data not shown). Our previous studies have reported that the suppression of cell proliferation by IFN- $\beta$ in HCC cell lines was primarily due to apoptosis (24). However, the present study was unable to confirm the induction of apoptosis by ME3738, suggesting that the mechanism of induction of IFN- $\beta$ by ME3738 may differ between non-neoplastic and neoplastic cells.

ME3738 was reported to increase the expression of IL-6 in the liver (26). From the point of view of host defense, IL-6 


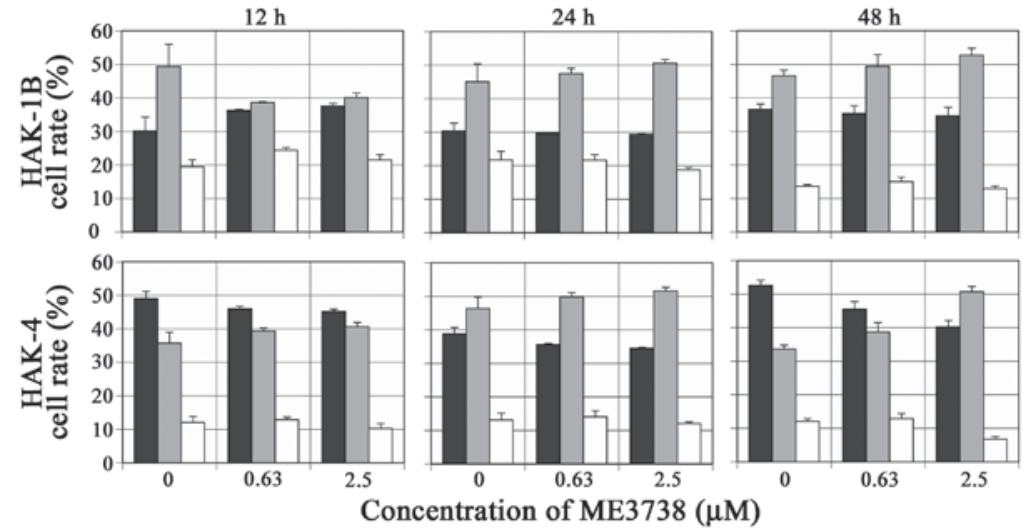

Figure 2. Cell cycle analysis [G1 phase (black bar), S-phase (grey bar), G2/M phase (white bar)]. In HAK-1B and HAK-4, the ratio of cells in the S-phase increased, whereas the ratio of cells in the G2/M phase slightly decreased or did not change, compared with those in the control at any time-point $12-48 \mathrm{~h}$ after the addition of ME3738. ME3738, 22 $\beta$-methoxyolean-12-ene-3 $\beta, 24(4 \beta)$-diol.



Figure 3. Antiproliferative effect of ME3738 in combination with PEG-IFN- $\alpha-2 b$. Cells were incubated with ME3738 in the presence of PEG-IFN- $\alpha-2 b$, and the relative viable cell number (\% of control) was determined after $72 \mathrm{~h}$ of culture. ME3738, 22 $\beta$-methoxyolean-12-ene-3 $\beta, 24(4 \beta)$-diol.

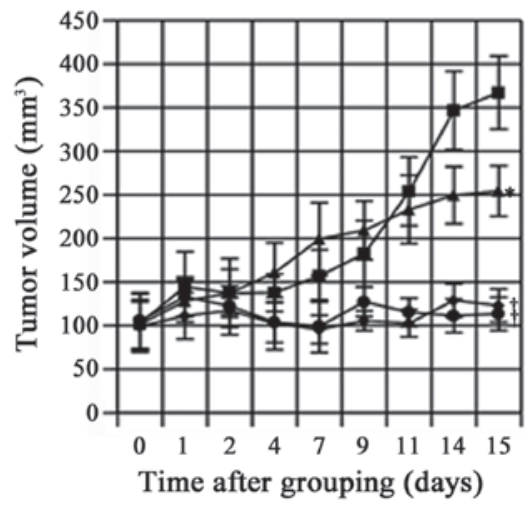

Figure 4. Time course change in estimated tumor volume of s.c. transplanted HAK-1B in nude mice. The mice received ME3738 alone (^), PEG-IFN- $\alpha-2 b$ alone $(\bullet)$, ME3738 and PEG-IFN- $\alpha-2 b(\bullet)$ or control $(\mathbf{\square})$. All the mice were sacrificed on day $15 .{ }^{*} \mathrm{P}<0.05$ vs. control; ${ }^{\dagger} \mathrm{P}<0.001$ vs. control. ME3738, $22 \beta$-methoxyolean-12-ene-3 $\beta, 24(4 \beta)$-diol. is a multifunctional cytokine that, not only plays an important role in the immune reaction, but is also involved in acute phase response and cell growth and differentiation. ME3738 is known to induce IL-6 by increasing the expression of Bcl-2 and Bcl-xL, which have anti-apoptotic effects, thereby protecting the cells from Fas-mediated death. Furthermore, the anti-apoptotic effects of IL-6 are reported to be mediated by downstream STAT3 signaling (27). Therefore, although it is not direct, ME3738 has an anti-apoptotic effect. We did not observe anti-proliferative effects of HCC cells mediated by apoptosis in the present study. Thus studies should be conducted. On the other hand, S-phase cell cycle arrest was observed in two of the HCC cell lines we studied. Ellington et al similarly reported that soyasaponin B inhibited the activation of cyclin-dependent kinase-2 and induced S-phase arrest in a colon cancer cell line (28). However, a different study found 
that saponins such as ginsenoside induced $\mathrm{G}_{0} / \mathrm{G}_{1}$ arrest in multiple cell lines (1), suggesting that cell-cycle regulation by saponin differs according to cell type or saponin source.

With regard to the suppression of tumor formation in nude mice, ME3738 alone significantly inhibited tumorigenicity compared with the control, but we found with PEG-IFN- $\alpha-2 b$ alone that tumor diameters at day 15 of administration were approximately the same as that at the start of the experiment, and combination treatment with ME3738 and PEG-IFN- $\alpha-2 b$ produced no additive or synergistic effects on tumor suppression, similar to the in vitro results. CD34 immunostaining revealed no differences in the number of blood vessels among the groups, indicating that ME3738 had no antiangiogenic effect. There was no significant difference on MIB-1, which is known to be a marker of cell proliferation in many tumors, among the groups. Tumor volume decreased significantly in the treatment groups with ME3738 as compared with the control. MIB-1 is detected in all the phases except $\mathrm{G}_{0} / \mathrm{G}_{1}$, and one of the reasons that no differences in MIB-1 expression were seen in the mouse tissue may be that, as ME3738 showed S-phase arrest in vitro, ME3738 treatment in HAK-1B-transplanted mice may have induced S-phase arrest, with the result that similar levels of MIB-1-positive cells were observed in the ME3738-treated mice and in the controls. In addition, S-phase arrest in vitro, while not remarkable, may help account for the fact that MIB-1 expression showed no change after ME3738 administration in vivo, regardless of the number of doses or length of observation period.

IFN has been widely used for therapies for chronic hepatitis C. ME3738 promotes the secretion of INF- $\beta$ and phase II trials of the combination treatment with ME3738 and PEG-IFN- $\alpha-2 \mathrm{a}$ were conducted to determine whether the combination treatment would increase the rate of patients achieving a sustained virological response (SVR). However, a clear additional effect on SVR was not confirmed in phase II trials (15). Furthermore, direct acting antivirals (DAA) radically altered the treatment of hepatitis C (29). Oral administration of DAAs, which acts directly to suppress HCV replication, is able by itself to achieve high rates of SVR, and as a result the use of IFN to treat chronic hepatitis $C$ no longer constituted an issue.

The introduction of DAAs was expected to further improve SVR rates and reduce the incidence of HCC associated with HCV (30-36). Nevertheless, it has been reported that even among patients who achieved SVR, some still develop HCC, and risk factors of $\mathrm{HCC}$ are known to affect the elderly, male gender, advanced liver fibrosis, and high AFP levels (30-36). In a rat bile duct ligation model, ME3738 was shown to inhibit hepatic stellate cell activation and collagen synthesis, resulting in the suppression of liver fibrosis (13). Furthermore, no significant adverse effects on the combination treatment of ME3738 and Peg-IFN- $\alpha 2 \mathrm{a}$ in the clinical trials have been reported thus far, and the safety of ME3738 treatment in chronic hepatitis patients has been confirmed (15). ME3738 may exert a protective effect against hepatocarcinogenesis through the inhibition of hepatic fibrosis. Our current study shows that, ME3738 suppressed cell proliferation to varying degrees in all the HCC cell lines we tested. In conclusion, our findings suggest that ME3738 may exert antitumorigenic effects in a wide range of HCC patients, and that when used in combination with current therapeutic medications it may function as a modulator to increase the antitumorigenic effect in HCC.

\section{Acknowledgements}

We would like to thank Ms. Akemi Fujiyoshi for her assistance in our experiment.

\section{References}

1. Rao AV and Gurfinkel DM: The bioactivity of saponins: Triterpenoid and steroidal glycosides. Drug Metabol Drug Interact 17: 211-235, 2000.

2. Hayashi K, Hayashi H, Hiraoka N and Ikeshiro Y: Inhibitory activity of soyasaponin II on virus replication in vitro. Planta Med 63: 102-105, 1997.

3. Simões CM, Amoros M and Girre L: Mechanism of antiviral activity of triterpenoid saponins. Phytother Res 13:323-328, 1999.

4. Gurfinkel DM and Rao AV: Soyasaponins: The relationship between chemical structure and colon anticarcinogenic activity. Nutr Cancer 47: 24-33, 2003.

5. Kim HY, Yu R, Kim JS, Kim YK and Sung MK: Antiproliferative crude soy saponin extract modulates the expression of IkappaBalpha, protein kinase $\mathrm{C}$, and cyclooxygenase-2 in human colon cancer cells. Cancer Lett 210: 1-6, 2004.

6. Sung MK, Kendall CW, Koo MM and Rao AV: Effect of soybean saponins and gypsophilla saponin on growth and viability of colon carcinoma cells in culture. Nutr Cancer 23: 259-270, 1995.

7. Spector D, Anthony M, Alexander D and Arab L: Soy consumption and colorectal cancer. Nutr Cancer 47: 1-12, 2003.

8. Hiwatashi K, Shirakawa H, Hori K, Yoshiki Y, Suzuki N, Hokari M, Komai M and Takahashi S: Reduction of blood pressure by soybean saponins, renin inhibitors from soybean, in spontaneously hypertensive rats. Biosci Biotechnol Biochem 74: 2310-2312, 2010.

9. Klein C, Wüstefeld T, Heinrich PC, Streetz KL, Manns MP and Trautwein C: ME3738 protects from concanavalin A-induced liver failure via an IL-6-dependent mechanism. Eur J Immunol 33: 2251-2261, 2003.

10. Kuzuhara H, Nakano Y, Yamashita N, Imai M, Kawamura Y, Kurosawa T and Nishiyama S: Protective effects of alpha1-acid glycoprotein and serum amyloid A on concanavalin A-induced liver failure via interleukin-6 induction by ME3738. Eur J Pharmacol 541: 205-210, 2006.

11. Fukumura A, Tsutsumi M, Tsuchishima M, Hayashi N, Fukura M, Yano H, Ozaki K and Takase S: Effect of the inducer of interleukin-6 (ME3738) on rat liver treated with ethanol. Alcohol Clin Exp Res (Suppl 1) 31: S49-S53, 2007.

12. Nomoto M, Miyata M, Shimada M, Yoshinari K, Gonzalez FJ, Shibasaki S, Kurosawa T, Shindo Y and Yamazoe Y: ME3738 protects against lithocholic acid-induced hepatotoxicity, which is associated with enhancement of biliary bile acid and cholesterol output. Eur J Pharmacol 574: 192-200, 2007.

13. Maeda K, Koda M, Matono T, Sugihara T, Yamamoto S, Ueki M, Murawaki Y, Yamashita N and Nishiyama S: Preventive effects of ME3738 on hepatic fibrosis induced by bile duct ligation in rats. Hepatol Res 38: 727-735, 2008.

14. Abe H, Imamura M, Hiraga N, Tsuge M, Mitsui F, Kawaoka T, Takahashi S, Ochi H, Maekawa T, Hayes CN, et al: ME3738 enhances the effect of interferon and inhibits hepatitis $\mathrm{C}$ virus replication both in vitro and in vivo. J Hepatol 55: 11-18, 2011.

15. Saibara T, Enomoto N, Kaneko S, Chayama K, Sata M, Imawari M, Onishi S and Okita K: Clinical efficacy of combination therapy with ME3738 and pegylated interferon-alpha-2a in patients with hepatitis C virus genotype 1 . Hepatol Res 44: 410-419, 2014.

16. Murakami T: Establishment and characterization of human hepatoma cell line (KIM-1). Act Hepatol Jpn 25: 532-539, 1984.

17. Yano H, Kojiro $M$ and Nakashima T: A new human hepatocellular carcinoma cell line $(\mathrm{KYN}-1)$ with a transformation to adenocarcinoma. In Vitro Cell Dev Biol 22: 637-646, 1986.

18. Yano H, Maruiwa M, Murakami T, Fukuda K, Ito Y, Sugihara S and Kojiro M: A new human pleomorphic hepatocellular carcinoma cell line, KYN-2. Acta Pathol Jpn 38: 953-966, 1988. 
19. Murakami T, Maruiwa M, Fukuda K, Kojiro M, Tanaka M and Tanikawa K: Characterization of a new human hepatoma cell line (KYN-3) derived from the ascites of the hepatoma patient. In: Proceedings of the Japanese Cancer Association. Jpn J Cancer Res, Tokyo, p292, 1988.

20. Yano H, Iemura A, Fukuda K, Mizoguchi A, Haramaki M and Kojiro M: Establishment of two distinct human hepatocellular carcinoma cell lines from a single nodule showing clonal dedifferentiation of cancer cells. Hepatology 18: 320-327, 1993.

21. Haramaki M, Yano H, Iemura A, Momosaki S, Ogasawara S, Inoue M, Yamaguchi R, Kusaba A, Utsunomiya I and Kojiro M: A new human hepatocellular carcinoma cell line (HAK-2) forms various structures in collagen gel matrices. Hum Cell 10: $183-192,1997$.

22. Utsunomiya I, Iemura A, Yano H, Akiba J and Kojiro M: Establishment and characterization of a new human hepatocellular carcinoma cell line, HAK-3, and its response to growth factors. Int J Oncol 15: 669-675, 1999.

23. Yano H, Iemura A, Haramaki M, Ogasawara S, Takayama A, Akiba J and Kojiro M: Interferon alfa receptor expression and growth inhibition by interferon alfa in human liver cancer cell lines. Hepatology 29: 1708-1717, 1999.

24. Ogasawara S, Yano H, Momosaki S, Akiba J, Nishida N, Kojiro S, Moriya F, Ishizaki $\mathrm{H}$, Kuratomi $\mathrm{K}$ and Kojiro M: Growth inhibitory effects of IFN-beta on human liver cancer cells in vitro and in vivo. J Interferon Cytokine Res 27: 507-516, 2007.

25. Hiasa Y, Kuzuhara H, Tokumoto Y, Konishi I, Yamashita N, Matsuura B, Michitaka K, Chung RT and Onji M: Hepatitis C virus replication is inhibited by 22beta-methoxyolean-12-ene-3beta, 24(4beta)-diol (ME3738) through enhancing interferon-beta. Hepatology 48: 59-69, 2008.

26. Kovalovich K, Li W, DeAngelis R, Greenbaum LE, Ciliberto G and Taub R: Interleukin- 6 protects against Fas-mediated death by establishing a critical level of anti-apoptotic hepatic proteins FLIP, Bcl-2, and Bcl-xL. J Biol Chem 276: 26605-26613, 2001.

27. Haga S, Ogawa $\mathrm{W}$, Inoue $\mathrm{H}$, Terui $\mathrm{K}$, Ogino $\mathrm{T}$, Igarashi $\mathrm{R}$, Takeda K, Akira S, Enosawa S, Furukawa H, et al: Compensatory recovery of liver mass by Akt-mediated hepatocellular hypertrophy in liver-specific STAT3-deficient mice. J Hepatol 43: 799-807, 2005.

28. Ellington AA, Berhow M and Singletary KW: Induction of macroautophagy in human colon cancer cells by soybean B-group triterpenoid saponins. Carcinogenesis 26: 159-167, 2005.
29. Kumada H, Suzuki Y, Ikeda K, Toyota J, Karino Y, Chayama K, Kawakami Y, Ido A, Yamamoto K, Takaguchi K, et al: Daclatasvir plus asunaprevir for chronic HCV genotype $1 \mathrm{~b}$ infection. Hepatology 59: 2083-2091, 2014.

30. Asahina Y, Tsuchiya K, Nishimura T, Muraoka M, Suzuki Y, Tamaki N, Yasui Y, Hosokawa T, Ueda K, Nakanishi H, et al: $\alpha$-fetoprotein levels after interferon therapy and risk of hepatocarcinogenesis in chronic hepatitis C. Hepatology 58: 1253-1262, 2013.

31. Ikeda M, Fujiyama S, Tanaka M, Sata M, Ide T, Yatsuhashi $H$ and Watanabe H: Risk factors for development of hepatocellular carcinoma in patients with chronic hepatitis $\mathrm{C}$ after sustained response to interferon. J Gastroenterol 40: 148-156, 2005.

32. Oze T, Hiramatsu N, Yakushijin T, Miyazaki M, Yamada A, Oshita M, Hagiwara H, Mita E, Ito T, Fukui H, et al; Osaka Liver Forum: Post-treatment levels of $\alpha$-fetoprotein predict incidence of hepatocellular carcinoma after interferon therapy. Clin Gastroenterol Hepatol 12: 1186-1195, 2014.

33. Nagaoki Y, Aikata H, Nakano N, Shinohara F, Nakamura Y, Hatooka M, Morio K, Kan H, Fujino H, Kobayashi T, et al; Hiroshima Liver Study Group: Development of hepatocellular carcinoma in patients with hepatitis $\mathrm{C}$ virus infection who achieved sustained virological response following interferon therapy: A large-scale, long-term cohort study. J Gastroenterol Hepatol 31: 1009-1015, 2016.

34. Nagaoki Y, Aikata H, Miyaki D, Murakami E, Hashimoto Y, Katamura Y, Azakami T, Kawaoka T, Takaki S, Hiramatsu A, et al: Clinical features and prognosis in patients with hepatocellular carcinoma that developed after hepatitis $\mathrm{C}$ virus eradication with interferon therapy. J Gastroenterol 46: 799-808, 2011.

35. Tokita H, Fukui H, Tanaka A, Kamitsukasa H, Yagura M, Harada $\mathrm{H}$ and Okamoto $\mathrm{H}$ : Risk factors for the development of hepatocellular carcinoma among patients with chronic hepatitis $C$ who achieved a sustained virological response to interferon therapy. J Gastroenterol Hepatol 20: 752-758, 2005.

36. Makiyama A, Itoh Y, Kasahara A, Imai Y, Kawata S, Yoshioka K, Tsubouchi H, Kiyosawa K, Kakumu S, Okita K, et al: Characteristics of patients with chronic hepatitis $C$ who develop hepatocellular carcinoma after a sustained response to interferon therapy. Cancer 101: 1616-1622, 2004. 